\title{
CONNOTAS.
}

REVISTA DE CRÍTICA Y TEORÍA LITERARIAS 


\title{
En el archivo personal de Jorge Ibargüengoitia: tres aportaciones críticas desde el análisis biográfico
}

\author{
Jorge Ibargüengoitia's personal papers: three critical \\ contributions from a biographical perspective
}

\author{
Alejandro Ramírez LÁmbarRy \\ Benemérita Universidad Autónoma de Puebla \\ alambarry.ffyl@gmail.com
}

Resumen:

Con base en una investigación biográfica sobre Jorge Ibargüengoitia, que nos llevó a la consulta de su archivo personal en la Universidad de Princeton y a la colección de testimonios orales de amistades como la de Ángela Gurría, entre otros, así como a la revisión bibliográfica de sus escritos y de su recepción, obtuvimos aportaciones críticas que refuerzan y renuevan algunos juicios sobre su vida y su obra. Dichas aportaciones las ordenamos bajo tres criterios: 1) historia/narrativa personal, 2) sociología literaria y 3) poética.

Palabras clave:

biografía, sociología literaria, Jorge Ibargüengoitia, archivo personal.

Abstract:

This biographical research centered in the figure of Jorge Ibargüengoitia is based on the consultation of his personal papers, kept by the Princeton University Library; interviews with close friends of his, like Ángela Gurria; and a revision of his works and their critical reception. Because of these, we obtained cri- 
tical input that both reinforce and renew some interpretations about his life and his work. Our contributions to the study of Ibargüengoitia's work and life are organized under three critical lines: 1) history and personal narrative, 2) sociology of literature, 3) personal poetics.

Keywords:

Biography, Sociology of literature, Jorge Ibargüengoitia, personal papers.

A finales de la década de los ochenta, Vicente Leñero escribió el primer intento de biografía sobre Jorge Ibargüengoitia, Los pasos de Lóper, en donde identificó atinadamente dos momentos clave en la vida del autor: su relación productiva y conflictiva con su maestro Rodolfo Usigli, y su lucha contra las figuras solemnes de la tradición literaria mexicana, patente en su crítica contra Alfonso Reyes. La biografía se documentó, sobre todo, en la correspondencia de Ibargüengoitia con Usigli y en el conocimiento del medio teatral mexicano que tenía Leñero. En el 94, el periódico Reforma le dedicó a Ibargüengoitia un número especial a diez años de su muerte. En él participaron los primeros académicos dedicados al estudio de su obra: Ana Rosa Domenella y Álvaro Ruiz Abreu. Joy Laville abrió el dossier, por su parte, con un texto biográfico: "Llevaba un sol dentro". En dicho testimonio narraba la rutina de trabajo de ambos creadores: a los dos les gustaba trabajar durante la mañana, por lo que después del desayuno cada uno se dirigía a su estudio a trabajar; volvían a verse a la hora de la comida y en la cena, después de la cual jugaban una partida de ajedrez o scrabble.

En 2002, Juan Villoro y Víctor Díaz Arciniega publicaron una edición crítica de El atentado/Los relámpagos de agosto en la reconocida colección Archivos/UNESCO. Arciniega desarrolló entonces una Cronología sumamente detallada de la vida del autor guanajuatense. Es, de hecho, el esfuerzo crítico más ambicioso para analizar y entender el momento histórico-cultural relacionado con la vida de Ibargüengoitia. A diferencia del texto de Leñero, el recorrido de esta cronología empieza en el año de nacimiento del autor y con- 
cluye diez años después de su muerte. Por su parte, financiado por la Cámara de Diputados del Estado de Guanajuato, en 2013, Horacio Muñoz Alarcón realizó una cronología ilustrada armada con pasajes de la obra autobiográfica de Ibargüengoitia: En primera persona, cronología ilustrada de Jorge Ibargüengoitia. Algo muy similar hizo María Cristina Secci en La realidad según yo la veo. La ley de Jorge Ibargüengoitia.

Como se observa, Jorge Ibargüengoitia ha sido estudiado desde la crítica biográfica de manera más o menos seria y constante en las últimas tres décadas, lo cual no es tan común en el caso de otros escritores mexicanos. Nuestro trabajo se inscribe en esta misma línea de investigación. Hemos ampliado, no obstante, las fuentes de investigación sobre su vida con la consulta de su arhivo completo (que se encuentra en la Universidad de Princeton) y que incluye su correspondencia, sus documentos personales y los borradores de sus textos. Consultamos de igual manera su obra literaria, que tiene una clara inclinación autobiográfica, así como los testimonios de amigos y familiares. Para mayor claridad, dividiremos nuestro material en tres niveles críticos: 1) historia/narrativa personal, 2) sociología literaria y 3) poética. ${ }^{1}$ La investigación que hemos realizado sobre Jorge Ibargüengoitia se centró en su vida como autor pero, al relizarla, obtuvimos resultados en estos tres niveles de la crítica literaria porque la biografía, además de ser un género híbrido - en la frontera entre la historia y la ficción— es un género con un gran potencial interdisciplinario. ${ }^{2}$ Nuestro interés en este artículo

${ }^{1}$ Véase también nuestro artículo "Los nuevos retos del viejo género de la crítica biográfica: el caso de Augusto Monterroso" donde aplicamos la misma clasificación crítica a la biografía del autor centroamericano Augusto Monterroso.

${ }^{2}$ Para el estudio de la biografía como un género crítico válido, véase a Ivan Jablonka, quien en su libro La historia es una literatura contemporánea. Manifiesto por las ciencias sociales, escribe: "La narración . . . no es el yugo de la historia, su mal necesario; constituye, al contrario, uno de sus recursos epistemológicos más poderosos" (146) y "La historia es la absoluta libertad de un yo en los límites absolutos que le fija la documentación” (194). Véase también François Dosse en El arte de la biografía. 
es, por un lado, aportar nuevas conclusiones a la vida y la obra de Ibargüengoitia y, por otro, dar prueba de esta solidez teórica e interdisciplinaria de una crítica biográfica que ha sido, en ocasiones, malinterpretada o simplificada como narraciones ingenuas y teleológicas que buscan desentrañar desde la infancia los motivos del genio y el talento del biografiado. ${ }^{3}$

\section{Narrativa personal}

El primer nivel crítico es el que se identifica mayormente con el género de la biografía: se trata del plano anécdotico, la narración de vida. Hay que enfatizar, sin embargo, que la vida del o la biografiado/a se debe sustentar siempre con una investigación pormenorizada de archivo, incluidos testimonios orales y otros documentos. En su artículo "The Art of Biography", Virginia Woolf advierte sobre la importancia de buscar la verdad sin olvidar la complejidad de la estructura literaria:

The biographer's imagination is always being stimulated to use the novelist's art of arrangement, suggestion, dramatic effect to expound the private life. Yet if he carries the use of fiction too far, so that he disregards the truth... he loses both worlds; he has neither the freedom of fiction nor the substance of fact. (cit. en Parke 43)

Es imposible llegar a un nivel de certeza totalmente objetivo y en esa imposibilidad puede filtrarse un alto grado de ficción, como han explicado críticos como John Worten y Hermione Lee. ${ }^{4}$ No obstan-

${ }^{3}$ Así lo hace, por ejemplo, Roland Barthes quien afirma que la biografía "es una novela que no se atreve a decir su nombre" (cit. en Dosse 308) y Pierre Bourdieu, al que analizaremos en el segundo apartado. Creemos, sin embargo, que en ambos casos se ataca a la biografía de tipo romántico.

${ }^{4}$ John Worten escribe en su artículo "The Necessary Ignorance of a Biographer": "Ignorance is banished, while we are in the grip of that calm and 
te, la seriedad y el compromiso de la investigación se debate en la contienda entre la ficción y el archivo histórico. Quien escribe, publica y, sobre todo, lee el resultado final debe evaluar los resultados de dicha contienda. Como lo dice Ivan Jablonka: "el investigador no pide al lector la suspensión voluntaria de la incredulidad (como en el relato de ficción), sino el rechazo sistemático de la credulidad" (247). En ocasiones, para despertar esta suspicacia en el lector y generar incluso una complicidad en el acto creativo, las biografías evidencian en la narración la apropiación de sus fuentes. ${ }^{5}$

En este caso, abordaremos un hecho de vida sumamente complejo y de difícil interpretación: un affaire romántico. Parte de la complejidad del acto radica en su divulgación. ¿Cómo evitar el carácter amarillista o voyeurista de la relación romántica clandestina? Otro problema es que los personajes involucrados pueden econtrarse todavía con vida y la divulgación de sus recuerdos puede resultarles molesta. Por último, se encuentra la dificultad de interpretar un documento sin conocer la intención de quien lo escribió, ni el contexto de su escritura. Teniendo esto en mente, decidimos sin embargo abordar este tema por lo que aporta al conocimiento de la vida y la obra del autor. En sus textos autobiográficos, Ibargüengoitia solía presentarse detrás de un velo de ironía. El humor que lo protegía de la solemnidad y la seriedad se desprende en sus diarios cuando narra su enamoramiento, así como el posible affaire y el término de este con la artista Ángela Gurría, "Gela” para Jorge Ibargüengoitia.

measured explanatory narrative: we comprehend all sides, command all points of view, know all there is to be known. This apparently seamless and omniscient narrative is, however, constructed out of a random survival of facts and letters and memoirs, and a random survival of relationships that can be known about" (232).

${ }^{5}$ Claire Tomalin en su biografía sobre Ellen Ternan escribe al final de un capítulo donde se ha narrado el affaire entre la biografiada y Charles Dickens: "This chapter has tried to make some sense of the known facts of the years between 1861 and 1865, and suggested a simple outline of a narrative to fit them" (cit. en Worten 241). 
Cuando Ibargüengoitia conoció en 1956 a Gela, ella era una joven de cabello negro lacio, de piel blanca y de una sensualidad natural y espontánea. Ella estudió Letras Españolas en la Facultad de Filosofía y Letras de la UNAM, pero dejó la carrera para dedicarse a la escultura. Eran vecinos, vivían a siete calles de distancia en el barrio de Coyoacán, por lo que organizaron comidas, viajes y fiestas con amigos. Por los apuntes de sus diarios, podemos asumir que él se enamoró de ella al poco tiempo de conocerse. El problema era que Gela era casada.

Debemos recordar que estamos a mediados de la década de los cincuenta. Para quien conozca la obra autoficcional de Ibargüengoitia, especialmente La ley de Herodes, sabrá que el personaje narrador de sus cuentos se presenta como alguien falible al fervor religioso, sobre todo después de sufrir fracasos eróticos. ${ }^{6} \mathrm{De}$ esta manera, escribe en su cuento "La vela perpetua": "me entró el fervor religioso. Iba a misa todos los días y comulgaba y le pedía a Dios Nuestro Señor y a la Santísima Virgen que me diera una compañera que fuera al mismo tiempo decente y cachonda" (81). Luego agrega: "me agarró la religión más fuerte que nunca y fui al Club Vanguardias y compré boleto para unos Ejercicios de Encierro, de los que organizaba el Padre Pérez del Valle en una casa que tenían los jesuitas en Tlalpan” (82). Termina este pasaje diciendo: "Por si alguien lo ignora, conviene adveritr que San Ignacio fue el que inventó el Lavado Cerebral y le puso por nombre Ejercicios Espirituales" (83). La ironía es clara y efectiva: a más frustración sexual, más fervor religioso. Al leer "La vela perpetua", dudamos si el cuento terminará con una relación sexual entre el narrador y el personaje de Julia o con la conversión del primero en sacerdote. El

${ }^{6}$ El carácter autobiográfico de La ley de Herodes lo identificó Huberto Batis, al escribir una reseña en 1979, donde afirmó que Ibargüengoitia había renovado el género con el humor de su estilo "personalísimo"; la suya era "una autobiografía, a diez años luz de las escritas por los jóvenes de Empresas Editoriales, tan solemnes" (Batis). María Cristina Secci realizó en La realidad según yo la veo. La ley de Jorge Ibargüiengoitia un estudio sobre la autoficción de su obra; y una de las obras principales de sus análisis fue justamente La ley de Herodes. 
final resulta, sin embargo, inesperado: la frustración sexual volvió al enamorado un escritor.

La investigación biográfica nos ayuda a agregar otra capa de significado al personaje de Ibargüengoitia. Para empezar, encontramos en el archivo personal del autor el libro Ejercicios espirituales de San Ignacio de Loyola, con el nombre "Jorge Ibargüengoitia" y el año de adquisición: 1952, escritos a mano con letra muy cuidada. E1 hecho de que conservara este libro entre sus papeles personales es también significativo, lo señala como un objeto que explica una etapa importante de su vida. ${ }^{7}$ Además de este libro, encontramos un diario de los años 57 al 58, los años en que conoció a Ángela Gurría y convivió con ella. En un pasaje de este diario escribe: "Ayer sucedieron algunas cositas. Todo el día tuve un deseo de confesarme. Un modesto deseo de confesarme. Salí, en dirección de Pilar, con intenciones de confesarme en el camino a la hora de la cursilería crepuscular... Si entro al cielo será porque está abierto para ciertas personas no muy respetables; los adúlteros" (Notebooks). ${ }^{8}$ Interpretamos este apunte como un conflicto personal serio del autor. Por un lado se trata de su enamoramiento con una mujer casada: "A esta mujer no puedo dejarla ir" (Notebooks), “[d]isponerse al máximo esfuerzo y que ella escoja" (Notebooks); y por otro lado, de su fe religiosa que, contra la ironía con la que se aborda en La ley de Herodes, se revela en este caso más seria. De hecho, cuando ella asumimos - termina la relación — en caso de que esta en realidad hubiera sucedido: es posible que todo fuera un coqueteo mal interpretado-, Ibargüengoitia descubre que ha perdido la fe: "Desde ese día prescindí de los sacramentos; sin que se opere en mi vida

${ }^{7}$ Puede tratarse, claro está, de una adquisición que realizó en su momento para la escritura del cuento. Nosotros nos inclinamos, sin embargo, a una lectura donde Ibargüengoitia se revela en realidad como una persona con fervor religioso.

${ }^{8}$ El aquí citado es uno de varios cuadernos archivados de forma numérica en la Biblioteca de la Universidad de Princeton. En este trabajo solo se cita el Notebook. (1). Se prescindió del número en las referencias parentéticas para evitar posibles confusiones con un número de página. 
otro cambio que la aparición de una conciencia de enorme y bellísima libertad" (Notebooks).

La naturaleza del diario refiere una escritura personal e íntima. Si bien puede estar escrito con ironía, su origen se ubica, de acuerdo con Philipe Lejeune, en la cultura católica y la práctica de la confesión. ${ }^{9}$ Creemos que, en sus diarios, Ibargüengoitia ha dejado la ironía y se revela angustiado, preocupado y cuestionado en su nivel más íntimo y personal. En otro apunte, por ejemplo, refiere un encuentro amoroso con Gela:

Anoche sucedió lo abominable... Al principio sentí arrepentimeinto, luego lo encontré como algo necesario -algo ha cambiado, en mí, algo se ha perdido, una defensa. ¿Por qué no aceptar el cambio en vez de procurar una actitud imposible? Esta mañana, sin embargo, solo quedó la vergüenza. (Notebooks)

El affaire romántico escrito en su diario es una historia muy parecida a la que se encuentra en "La vela perpetua", incluso en su final, pero aquí los recursos narrativos son distintos: el narrador de sus diarios personales sufre con pesar casi existencial la decepción amorosa, mientras que el del cuento sufre el rechazo con una distancia crítica que le aporta el humor. Es importante mencionar que en el caso de "La vela perpetua" se narra probablemente el romance fallido del autor con la directora de teatro Luisa Josefina Hernández, sucedido en $1952 .{ }^{10}$ Frente a esto tenemos, en los pasajes del diario, un po-

9 "Throughout the Middle Ages we find references to this technique, which was restricted to religious communities and gradually became part of the preparations for confession" (On Diary 55).

${ }^{10}$ Es posible asumir que el personaje de "La vela perpetua" se refiere a Luisa Josefina Hernández debido a elementos textuales del cuento que coinciden con hechos históricos (beca en Nueva York, trabajo en el medio teatral, curso compartido en la UNAM, entre otros), además de las mismas declaraciones de la directora, que debió sentirse aludida y escribió en Memorias. Luisa Josefina Hernández: "Ibargüengoitia fue mi compañero en la carrera, en las becas del Centro de 
sible affaire frustrado con Ángela Gurría en 1957. Son cinco años de diferencia, pero la reacción es muy parecida en ambos casos: el supuesto fervor y la decepción religiosa. Por este recuento personal y su posibilidad de lectura, que vuelve más compleja la figura de Jorge Ibargüengoitia, este aspecto de la biografía en el nivel de la narrativa personal es sumamente importante.

\section{Sociología literaria}

Abordaremos ahora el segundo nivel crítico de nuestra investigación biográfica, el de la sociología literaria. Sabemos que Pierre Bourdieu, teórico fundamental de esta teoría, se oponía al género de la biografía. En Las reglas del arte escribió:

Tratar de comprender una vida como una serie única y suficiente por sí misma de acontecimientos sucesivos sin otro vínculo que la asociación a un "sujeto" cuya constancia no es, indudablemente, más que la de un nombre propio, es casi tan absurdo como tratar de dar razón de un trayecto en el metro sin tomar en cuenta la estructura de la red, es decir, la matriz de las relaciones objetivas entre las distintas estaciones. (426; traducción mía)

Entendemos el comentario de Bourdieu como una crítica al género de la biografía romántica donde se atribuye una gran agencia al individuo. ${ }^{11}$ Creemos, no obstante, que el propio Bourdieu aportó

Escritores, en la Rockefeller de Nueva York. Seis años enteritos con sus días y, por fortuna, sin sus noches... Yo, como compañera suya, era uno de sus avatares" (99). Y agrega: " me denunció en cuanta letra impresa halló a la mano, porque estaba obsesivo” (100).

${ }^{11}$ Este tipo de biografía la vemos por ejemplo en las anécdotas que cuenta Richard Altick en su libro The scholar adventurers y, más recientemente, en el libro de Richard Holmes Footsteps: Adventures of a Romantic Biographer. De hecho, gran parte de la escuela inglesa de biografía todavía se sitúa en este grupo que da prioridad, sobre el contexto social, a la narrativa de vida. 
herramientas que actualizaron una biografía menos individualista y de narración teleológica. Gracias a la sociología literaria podemos estudiar ahora las ideas políticas, el carácter económico, religioso o laboral de una época mediados por la perspectiva del campo literario. Es decir, su aportación sirvió como apoyo teórico y metodológico a una disciplina menos ingenua y centrada, en cambio, en las complejas relaciones entre el individuo y su contexto. El mismo libro de Las reglas del arte nos puede servir de modelo. Cuando Bourdieu aborda la génesis y el fortalecimiento del campo literario en la Francia del siglo XIX, intercambia capítulos biográficos ("Baudelaire el Fundador", "El punto de vista de Flaubert"), con otros enfocados en la poética del autor ("Escribir bien lo mediocre") y otros de visión social mediada por el arte ("Las condiciones éticas de la revolución estética”). Este es el modelo de biografía en el que se inscribe nuestra propuesta. ${ }^{12}$

En el caso específico de Ibargüengoitia, nuestro interés es ubicar el cambio, en el México de medio siglo, de la figura del autor aficionado al profesional. ${ }^{13}$ Para ello nos apoyamos en sus documentos personales, en especial en su libro de contabilidad y en su correspondencia. En noviembre de 1957, Ibargüengoitia vendió la hacienda que heredó de su padre en Irapuato, Guanajuato. Era la última propiedad que quedaba del pasado oligárquico de la familia. A comien-

${ }^{12}$ Algunos ejemplos de este tipo de biografía en nuestra tradición latinoamericana son Las trampas de la fe de Octavio Paz, A salto de mata: Martín Luis Guzmán en la Revolución mexicana de Susana Quintanilla y Alejandra Pizarnik de César Aira.

${ }^{13}$ Los conceptos de escritor profesional y aficionado provienen del artículo de Ángel Rama "El boom en perspectiva". Rama refiere que el autor profesional debe cumplir con un ritmo productivo constante y suele abordar temáticas del momento. Su producción es en ocasiones descuidada, sin maduración suficiente, pero tiene a la literatura como empleo único, es decir, cuenta con una concentración exclusiva en su obra y en la publicidad de la misma. Rama ubica la consolidación de este autor durante los años del Boom. El escritor aficionado, que precede y sobrevive a esta época, es alguien más inclinado al hedonismo y a la inspiración, sus obras pueden ser "geniales y fragmentarias improvisaciones" (195); tiene una idea de la literatura como sacerdocio, territorio fuera del mercado, aunque para subsistir cuenta con un trabajo alterno, que suele estar en el medio político, editorial o educativo. 
zos del año siguiente, compró un libro de contabilidad, Sistema Roca. Al igual que con los Ejercicios espirituales escribió en la primera página con letra muy cuidada su nombre, dirección y año. En 1958 se registran cuatro meses con ingresos, todos de la editorial Novaro México; parece que se trataba de pagos por traducciones. El siguiente año, 1959, escribió mes por mes: "Sin ingresos" (Account book). En 1960 tiene dos ingresos y, en 1961, tres. La precariedad económica es notable hasta 1962, cuando empieza a trabajar para la Revista de la Universidad de México y recibe un salario mensual.

En este caso, lo más significativo es que Ibargüengoitia haya, en primer lugar, adquirido este libro de contabilidad justo cuando iniciaba su vida de escritor, habiendo terminado sus estudios y vendido su última propiedad familiar. Además de esto, destaca el hecho de que registrara, año con año, mes con mes, el no haber recibido ningún ingreso. Se trata de la actitud de un escritor profesional, de alguien que desea vivir de sus escritos, que entiende la literatura como una actividad artística que es también económica. El autor profesional, como lo indica Ángel Rama, requiere de una disciplina férrea que le dé una presencia en el medio con publicaciones periódicas:

el escritor que se ha profesionalizado deja atrás definitivamente tanto la "inquerida bohemia" como la "inspiradora musa" a las que debimos tantas geniales y fragmentarias improvisaciones que no tuvieron sucesión, porque ahora deviene un productor, a imagen de cualquier otro trabajador de la sociedad. Más estrictamente, ocupa dentro de la sociedad un lugar semejante al del empresario independiente que coloca periódicamente objetos en un mercado de ventas y aunque su sistema productivo sigue siendo en la mayoría de los casos artesanal, tal como lo percibiera Valéry, trabaja para un mercado desarrollado, lo que le impone el conocimiento de sus ásperas condiciones, sus líneas tendenciales, sus preferencias, o desdenes. (195)

En menos de una década, Ibargüengoitia escribió más de diez obras de teatro y seis guiones de cine. Se sometía a una disciplina férrea de 
creación. Sus temáticas seguían de cerca el interés del medio cultural mexicano. Por ejemplo, en 1959, a medio siglo de la conclusión de la Revolución y a siglo y medio del fin de la guerra de Independencia, escribió una obra con tema histórico, La conspiración vendida. Fue además muy consciente del mercado, no tuvo ningún problema cuando en 1955 Álvaro Custodio cambió el nombre de su obra Clotilde en su casa por el de Adulterio exquisito, esto con el fin de atraer un mayor público. Su verdadero problema, que lo llevó finalmente a renunciar al teatro, fue que este nunca le aportó el dinero necesario para vivir. Salvo sus primeras dos obras, ninguna otra volvió a escenificarse. La leyenda "Sin ingresos", que escribió mes con mes en su libro de contabilidad es, por lo mismo, una advertencia contra uno de los mayores peligros de la creación, y un anhelo, que, veinte años después, se haría realidad. ${ }^{14}$

En 1978, Carmen Balcells aceptó ser su agente literaria. Él lo había intentado sin éxito cuatro años antes, cuando ganó el Premio Novela México con Estas ruinas que ves. Sin embargo, después de la publicación de Las muertas y de la gran recepción que tuvo con una reseña elogiosa de Ángel Rama y otra de Octavio Paz, la agente catalana aceptó el compromiso, bajo sus propias reglas. Le pidió a Ibargüengoitia la exclusividad en el control de toda su obra, 10\% de comisión y un contrato con vigencia de cinco años, renovable. Él estuvo de acuerdo con todo. Veinte años después de escribir "Sin ingresos" durante los doce meses del año, su destino estaba en las manos de la agente literaria más importante de la lengua española.

${ }^{14}$ En este anhelo de poder vivir de la escritura, Ibargüengoitia recorrió un trayecto muy similar al de los escritores modernistas (como lo describe Julio Ramos en Desencuentros de la modernidad en América Latina). Ibargüengoitia ingresó al periódico Excélsior invitado por Julio Sherer García en diciembre de 1968; publicaba dos textos de opinión por semana. Sin embargo, cuando decidió escribir Estas ruinas que ves pidió una licencia de medio año en el periódico para dedicarse exclusivamente a su novela. Y después, cuando reunció a Excélsior, pudo escribir finalmente la novela Las muertas. Es decir que, si bien el trabajo le sirvió para poder vivir de su escritura, no le permitía dedicarse a proyectos más ambiciosos como lo fueron sus novelas. 
Podemos ver entonces el recorrido a la profesionalización, desde el autor que en su juventud tuvo siempre la necesidad y el deseo de obtener dinero con sus obras, que escribió con una disciplina férrea y que era muy consciente del interés temático del medio literario y del mercado cultural, hasta el otro que, en su madurez, dio el paso definitivo al contratar como agente a Balcells. En menos de un mes, ella le pidió volver a firmar los contratos de todas sus novelas con Joaquín Mortiz. Entre los cambios significativos incluyó un aumento de 10 a 12\% cuando se superaba la venta de 30 mil ejemplares por cada título y la necesidad de renovar el contrato cada tres años. Díez-Canedo, que nunca respondía una carta, le escribió de inmediato lamentando su decisión:

El martes y el jueves tuvimos, en dos sesiones, una discusión perfectamente circular y repetitiva, en la que Joaquín pasó varias veces por estas posiciones y otras. A) "Si usted quiere que firme este documento, lo firmo, porque yo firmo lo que usted quiera". B) "En realidad, lo que yo debería hacer, es decirle a usted, aquí están sus libros, váyase con Carmen Balcells”. C) "¿Por qué, si usted y yo hemos tenido tratos durante quince años sin ninguna dificultad, vamos ahora a firmar un contrato fechado hace un mes en Barcelona? (Carmen Balcells)

Tenemos aquí el encuentro de dos mundos: el autor aficionado contra el autor profesional, y el editor de una pequeña empresa cultural contra un agente literario que trabaja con los grandes consorcios. ${ }^{15}$ Al final, lo sabemos, Balcells logró darle la visibilidad y el

${ }^{15}$ Rama define en "El boom en perspectiva" la lógica de una pequeña empresa cultural como aquella que: 1) cuenta con una figura significativa de editor; 2) enfrenta un factor de riesgo alto en apuestas a escritores poco comerciales con temáticas y estilo arriesgado; 3) cuenta con una diversidad de títulos y grandes tirajes - pocket book- de obras consideradas fundamentales que aprovecharon el crecimiento de la sociedad lectora antes del boom; 4) realiza una importación de autores sugerentes, interesantes a una minoría atenta (177). Mientras que los grandes consorcios: 1) reemplazan la figura del editor por un grupo editorial; 2) apuestan a 
dinero que Ibargüengoitia siempre soñó. Trabajó como traductor, reseñista, profesor y articulista (en el periódico Excélsior) hasta que, en 1982, pudo finalmente vivir de sus regalías. Su obra fue traducida y publicada al inglés y al francés en 1983. Joaquín Mortiz fue adquirida por el Grupo Planeta alrededor del año 1982 y la obra de Ibargüengoitia ha permanecido desde entonces con este grupo: su difusión es sumamente exitosa.

\section{Poética}

Hemos analizado en el apartado anterior la idea de escritor y de medio literario que poseía Ibargüengoitia; en este otro nos enfocaremos en su visión de la literatura. Obtenemos nuestra interpretación de dos de sus prácticas de escritura. La primera tiene que ver con los cuadernos que lo acompañaban siempre en la creación de una novela. Ibargüengoitia escribía las versiones de sus novelas de corrido hasta detenerse en un momento que podía haberle parecido flojo, aburrido o, de manera muy distinta, un momento clave en la historia. Después tomaba un cuaderno en el que apuntaba sus impresiones de lectura. La segunda práctica tiene que ver con la manera en que abrevaba de su propia experiencia para recrear tramas y personajes de sus novelas. No es nuestra intención probar si aquello que relata en sus textos de ficción era verdad o no. Queremos, en cambio, destacar esta voluntad de retomar aspectos personales que ubican sus novelas en espacios locales reconocibles, así como un lenguaje coloquial de gran oralidad como punto importante de su poética literaria. En este caso contamos de igual manera con sus cuadernos y, además, con su correspondencia personal.

títulos "con un alto margen de confiabilidad de ventas", autores como "marca", o temáticas actuales que sean noticia (178); 3) reducen títulos, temas y autores para realizar, en cambio, grandes tirajes en grupos temáticos o de autores; 4) utilizan las fronteras políticas como fronteras para la concentración de mercado. 
Empecemos con los cuadernos que acompañaron su proceso creativo. No encontramos en ellos una postura poética declarada ni ideales estéticos, tampoco se menciona a otros autores ni lecturas que nos sirvan para analizar una relación intertextual o para determinar la afiliación a una tradición literaria específica. Sus cuadernos cumplían más bien con fines prácticos. Así lo vemos, por ejemplo, en aquellos que acompañaron al autor durante la escritura de Las muertas, novela que le tomó trece años concluir. La primera versión del texto, inspirado en el caso de las Poquianchis, fue una suerte de crónica narrada en primera persona. Al releer el texto, en 1966, no le satisfizo y asumimos que pensó en una estructura y género más apegado a la novela. Uno de sus primeros apuntes revela que buscaba más complejidad narrativa: "la historia se vuelve plural, muchas voces; compleja la cronología. Habrá textos narrados desde 10 años hasta 8 días antes del presente de la acción" (Las muertas). Había consultado el expediente del caso, pero las voces de las víctimas estaban siempre mediadas por la escritura leguleya del burócrata que las registró. Pudo haber pensado en entrevistar a las involucradas, pero su timidez — como declaró después en una entrevista- lo detuvo. ${ }^{16}$ La solución para la pluralidad de voces le vino el 31 de diciembre de 1974, fecha en la que escribió en su cuaderno:

Pensamiento de fin de año: Entre el viaje a la costa y la vida de Beto (también Simón, Juan González), se abre un capítulo intitulado 'Almanaque de las Baladro' que contendrá frases notables dichas por las hermanas, y sucesos de sus vidas, contados con mucha brevedad, que nos permitan esclarecer su personalidad. (Las muertas)

Otro problema significativo de Las muertas fue la voz narrativa, que cambió constantemente. En una primera versión de 1965, el narrador estaba en primera persona y era muy similar, en el uso del

${ }^{16}$ If I had been Truman Capote, I would have gone round and interviewed everybody, got many tapes, but I'm very bad at that, I'm very shy. So I invented the characters, they are composite images of different people I know (cit. en Herbert). 
humor irónico y de datos autobiográficos, al de los cuentos de $L a$ ley de Herodes. Diez años después de esa primera versión, escribió en un cuaderno: "El libro de las Baladro va a estar presentado, comentado y ordenado por Paco Aldebarán (yo: Estas ruinas)" (Las muertas). Para entonces había ya terminado su novela Estas ruinas que ves, narrada por el mismo Paco Aldebarán. Esta idea, sin embargo, no le resultó porque ya para el siguiente año dudaba, según lo expresó en un cuaderno con fecha del 4 de enero de 1976: "El caso de Blanca. Posibilidades. El narrador dice cómo se ponía la Calavera al hablar de Blanca. O bien abre con la Calavera. O bien pasa del relato de la Calavera, al del libertino, al album, a la descripción de la enfermedad a la curación". En otro cuaderno, fechado el 14 de mayo del mismo año, con título Nueva Tercera Versión, escribe: "El narrador estará fuera de la novela. Es quien escribe la novela" (Las muertas). Sabemos que esta fue la decisión final. Contamos, sin embargo, con una carta que Ibargüengoitia le escribió a Joy Laville en 1970, donde ya se expresaba la misma solución: "Sigo pensando en cómo corregir la chingada novela y llego a la conclusión de que quizá la manera correcta de hacerla es que ocurra en la cabeza del narrador, a partir del hecho consumado y caminando hacia atrás (en tiempo) en busca de aclaración" (Laville). Es decir, que Ibargüengoitia dio con su narrador seis años antes de la fecha en que volvió a encontrarlo, ahora con más convicción y certeza.

Tenemos cuadernos como el de Las muertas en casi todas sus novelas. En ellos se desarrollan problemas muy puntuales, relacionados con hechos específicos de la trama: si era necesario hacer cambios en los personajes, el espacio o el tiempo de la acción; si debía realizar correcciones o añadidos, entre otros. La suya era una poética que se enfocaba en cada uno de los componentes de la obra como si esta funcionara como una máquina cuyo objetivo final era atrapar la atención de un lector ideal que exigiera entretenimiento y complejidad formal; ${ }^{17}$ de ahí que todas sus novelas practica-

${ }^{17}$ El símil entre la obra literaria y una máquina quizá le habría gustado: Ibargüengoitia estudió la carrera de Ingeniería de Minas y Metalurgia. 
ran géneros considerados como comerciales o, en algún momento, menores (autobiografía, melodrama, histórico, policíaco y de crónica). Estos géneros, sin embargo, los subvirtió por medio de la parodia y de una estructura sumamente compleja, que es la que Ibargüengoitia revisaba constantemente en sus cuadernos.

Veamos ahora la segunda práctica literaria enfocándonos en su última novela incompleta, a la que posiblemente iba a titular Isabel cantaba. Contamos con manuscritos, cuadernos y correspondencia que hacen referencia a esta novela. En el caso de los manuscritos, tenemos al menos diez que terminan de manera abrupta en distintos pasajes. En casi todos el inicio y el entramado de la historia es claro, pero carecemos de su posible densenlace. Es posible afirmar que se trataba, por lo tanto, de un texto autoficcional: la trama alude, por un lado, a sus recuerdos de infancia (hijo de una familia adinerada venida a menos) y, por otro, a los de un affaire romántico frustrado, muy similar al de su cuento "La vela perpetua" (salvo que, en este caso, el narrador frustrado es un guionista de cine y la mujer que desea sin lograr enamorarla es una actriz). Podemos afirmar, además, que la mujer ya no es Luisa Josefina, sino Ángela Gurría. En una carta del 8 de agosto de 1981, que Ibargüengoitia le escribió a su entonces gran amiga, le dice: "Esta novela se llamará Isabel cantaba.* Espero terminarla algún día y que te guste. ${ }^{*}$ Te aseguro que te reconocerás pero no te ofenderás". Otro hecho que nos inclina a pensar en la autoficción es el cuaderno de apuntes que inició al momento de obtener la idea de su novela. En él narró varios pasajes autobiográficos, como sus recuerdos de infancia en la hacienda familiar de San Roque:

EJERCICIOS DE MEMORIA que sería un buen preámbulo —el relato no el libro- para ISABEL CANTABA y el nuevo ciclo de novelas que se presenta en el horizonte. Tres o cuatro novelas sobre "la capital" con personajes basados en la realidad pero con tramas ligeramente —o más - ficticias... Ahora que examino lo que he pensado decido que está bien. Hacer algo rigurosamente autobiográfico que sea interesante de por sí, de un tamaño elástico. (Isabel...) 
Al final, Ibargüenoitia eliminó el libro sobre sus recuerdos de infancia "por deprimente" (Isabel...) y se enfocó únicamente en los años de la adolescencia, de la universidad estudiando teatro y del affaire romántico frustrado. En el apunte citado, Ibargüengoitia refiere un proyecto más vasto, con otros libros que estarían incluidos en los "ejercicios de memoria". Pero como hemos visto y han analizado críticos como María Cristina Secci, la obra temprana de Ibargüengoitia es sumamente autoficcional; en especial, La ley de Herodes. Esto nos da pauta para nuestra siguiente intepretación que, más que aludir a la veracidad o no de lo narrado, o a su tendencia o no a la autoficción, nos interesa por lo que representa en la poética de Ibargüengoitia. La suya es una escritura que ocupa espacios hasta entonces poco abordados: la provincia mexicana y el medio cultural de la capital del país. ${ }^{18}$

Antes de Ibargüengoitia, la provincia y el campo habían sido el escenario de la Revolución traicionada; escenario de luchas y dramas, de violencia y miseria. La capital era el espacio donde convivían de manera conflictiva la modernidad, la colonia y lo prehispánico. En ambos casos, la oralidad solía estar restringida a la voz de los personajes. ${ }^{19}$ Con Ibargüengoitia tenemos un narrador coloquial (suele estar en primera persona) con escenarios de la clase media cultural citadina o de provincia. Esta novedad se debe, en parte, al hecho de que usaba para sus tramas anécdotas personales y personajes de su entorno más cercano. La literatura para él debía ser una maquinaria

${ }^{18}$ Esto mismo notó Guillermo García Oropeza en su reseña sobre La ley de Herodes: "Ibargüengoitia alcanza un medio que urgía ironizar: el de los brillantes mexicanos del aquel (sic) Renacimiento expresivo que prestaba sus luces a la Universidad, la Zona Rosa y las Editoriales. El México de la Nueva Cultura de Clase Media, que recibía becas, que mandaba construir casas en arquitectura moderna, que estudiaba Filosofía y Letras, que iba al teatro, a San Antonio, a Nueva York, a París. México motorizado y anglificado; curiosa sociedad burguesa que se encanta leyendo libros sobre la Revolución Socialista. Mexico Junior” (García).

${ }^{19}$ Claro está que hay excepciones, la más notable para la literatura del campo es Juan Rulfo; y para la citadina, Carlos Fuentes y, poco antes de él, Luis Spota (Casi el paraíso 1956). 
de mecanismo complejo pero presentada en un espacio reconocible para el/la lector/a. Esto que podría parecer ahora algo natural, no lo era tanto en una época donde la escritura anhelaba semejarse a modelos de gran complejidad formal, provenientes en su gran mayoría de regiones europeas y estadounidenses. ${ }^{20}$

La crítica biográfica obliga a la investigación del archivo personal del autor, incluidos los testimonios orales de amistades, familiares y colegas, a la vez que de las fuentes bibliográficas tradicionales. Si no se entiende como un anecdotario de vida, como una narración centrada en un individualismo exacerbado y sí, en cambio, como una crítica interdisciplinaria de carácter híbrido en un balance entre individualismo y determismo social, dicha crítica nos puede aportar conclusiones sólidas.

Por ejemplo, el estudio de la vida y la obra de Jorge Ibargüengoitia nos aportó resultados significativos para leerlo como un personaje complejo con una preocupación religiosa y existencial genuina (sobre todo cuando sufría de relaciones afectivas no correspondidas), que abordó alternando entre el humor y la seriedad. En una perspectiva menos individual y más determinista, Ibargüengoitia formó parte de una generación de escritores que vio el sueño de los modernistas concretarse en la figura del escritor profesional. En ese sentido, él fue uno de varios que trabajó e hizo lo posible para vivir de su literatura, y fue uno de pocos que lo logró. Sus últimos tres años de vida en París los dedicó exclusivamente a su escritura y a la promoción de su figura autoral. Por último, un escritor es, sobre todo, alguien con una idea muy clara de lo que es y no es literatura, con una poética que en ocasiones expresa de manera abierta y crítica, y en otras, de manera más velada en su obra. Es posible saber, por medio de sus cuadernos y su correspondencia, que la poética de Ibargüengoitia daba prioridad a la oralidad, al lenguaje coloquial y

${ }^{20}$ Ejemplo de ese prejuicio contra la oralidad y las tramas citadinas de clase media fue la clasificación por parte de Margo Glantz, con gran éxito mediático, entre autores de la onda (que narran sus aventuras adolescentes con slang) y autores de escritura (cuya preocupación es el lenguaje y la estructura). 
sencillo; sus espacios fueron siempre mexicanos, ya sea por referencia directa o por contexto; y abrevó, no solo de obras consagradas (alguna vez afirmó haberse puesto a leer En busca del tiempo perdido en francés, lo que consideró una dura prueba), sino también de los géneros supuestamente menores que suelen atrapar la atención del lector por su estructura convencional, que él, sin embargo, cambió con el uso de la parodia y de estructuras narrativas complejas.

\section{Bibliografía}

Altick, Richard. The scholar adventurers. The MacMillan Company, 1951.

Batis, Huberto. "El mundo de los libros". Suplemento Sábado, Unomásuno, no. 22, octubre 1979.

Bourdieu, Pierre. Les règles de l'art. Genèse et structure du champ littéraire, Éditions du Seuil, 1998.

Díaz Arciniega, Víctor. "Cronología”. Ibargüengoitia, El atentado. Los relámpagos de agosto, Colección Archivos, 2002.

Dosse, François. El arte de la biografía. Entre historia y ficción. Universidad Iberoamericana, 2011.

Gaitán, David. Memorias Luisa Josefina Hernández: Ediciones El Milagro y Universidad Autónoma de Nuevo León, 2016.

García Oropeza, Guillermo. "Reseña La ley de Herodes". El informador, mayo 1972.

Glantz, Margo. “Onda y escritura: jóvenes de 20 a 33”. Biblioteca Virtual Miguel de Cervantes, 2006, cervantesvirtual.com/nd/ ark:/59851/bmcvq3c2

Herbert, Hugh. "Hugh Herbert meets the Mexican novelist, Jorge Ibargüengoitia. No holds barred". The Guardian, 18 de marzo de 1983.

Holmes, Richard. Footsteps: Adventures of a Romantic Biographer. Vintage Departures, 1985.

Jablonka, Ivan. La historia es una literatura contemporánea. Manifiesto por las ciencias sociales. Fondo de Cultura Económica, 2016.

Leñero, Vicente. Los pasos de Ibargüengoitia. Joaquín Mortiz, 2009. 
Ibargüengoitia, Jorge. Account book. Jorge Ibargüengoitia Papers, C1334, Manuscripts Division, Department of Rare Books and Special Collections, Princeton University Library.

. El atentado. Los relámpagos de agosto. Edición crítica coordinada por Juan Villoro y Víctor Díaz Arciniega, Colección Archivos, 2002.

. Balcells, Carmen 1968-2008. Jorge Ibargüengoitia Papers, Manuscripts Division, Department of Rare Books and Special Collections, Princeton University Library.

. Carta a Ángela Gurría. 04 diciembre 1976. Colección personal de la remitente.

- Carta a Ángela Gurría. 08 agosto 1981. Colección personal de la remitente.

. La ley de Herodes. Joaquín Mortiz, 2003.

- Isabel cantaba; Jorge Ibargüengoitia Papers, C1334, Manuscripts Division, Department of Rare Books and Special Collections, Princeton University Library.

. Las muertas. Jorge Ibargüengoitia Papers, C1334, Manuscripts

Division, Department of Rare Books and Special Collections, Princeton University Library.

. Laville, Joy. Jorge Ibargüengoitia Papers, C1334, Manuscripts Division, Department of Rare Books and Special Collections, Princeton University Library.

- Notebooks (1). Jorge Ibargüengoitia Papers, C1334, Manuscripts Division, Department of Rare Books and Special Collections, Princeton University Library.

Laville, Joy. "Llevaba el sol adentro. Imágenes de Jorge". Vuelta. no. 100, volumen 9, marzo 1985.

Muñoz Alarcón, Horacio. En primera persona. Cronología ilustrada de Jorge Ibargüengoitia. Cámara de Diputados, 2008.

Parke, Catherine N. Biography. Writing lives. Routledge, 2002,

Rama, Ángel. "El boom en perspectiva". Signos Literarios, vol. 1, no. 1, enero-junio 2005, pp. 161-208.

Secci, Cristina M. La realidad según yo la veo. La ley de Jorge Ibargüengoitia. Ediciones La Rana / Biblioteca Montaigne, 2013.

Worten, John. "The Necessary Ignorance of a Biographer". The Art of Literary Biography, Oxford University Press, 1995. 